\title{
Trajetória de 甘remirĩ Arapasso: movimento indígena e resistência na universidade
}

\author{
Virgínia Braga Fonseca ${ }^{1}$
}

DOI: http://dx.doi.org/10.20435/tellus.v19i39.636

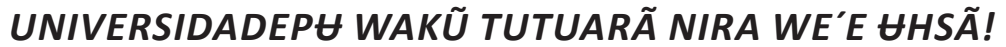 (SOMOS RESISTÊNCIA NA UNIVERSIDADE!)}

O Brasil é conhecido pela diversidade cultural de povos indígenas e tradicionais. Herança que nos foi deixada pelos ancestrais, a qual norteia a nossa resistência, sobretudo nós povos indígenas da Amazônia. Muitas foram as formas coloniais que tentaram nos aprisionar e, desde a descoberta do látex (borracha), o contexto do suposto progresso ou do desenvolvimento econômico afetou toda a região, do hoje, estado do Amazonas. A urbanização dos espaços, a industrialização, a apropriação dos meios de produção e as formas de trabalho inspiradas nos modelos de países capitalistas, produziu inúmeras dificuldades.

Apesar das dificuldades impostas, nós povos indígenas (23 etnias) do Rio Negro contamos com o ativismo evangelizador da Igreja Católica teve forte influência na área por intermédio das Carmelitas, sobre as 23 etnias.

Nosso povo Arapasso surgiu em uma das muitas cachoeiras do Alto Rio Negro em um orifício (buraco) da grande pedra, como contava meu pai, ensinando-nos a nossa história, o trajeto percorrido pela cobra grande permitiu que os nossos ancestrais, subissem os rios e assim surgiram os povos indígenas.

Assim, meu pai e minha mãe, meus grandes sábios, começavam a contar a trajetória de cada um dos parentes. Jovens, minha mãe veio descendo o rio Papuri e meu pai o rio Uaupés. Passaram por São Gabriel da Cachoeira, descendo o Rio Negro, ambos ficaram em "Tapuruquara” (buraco de tapurú), atualmente, município de Santa Isabel do Rio Negro.

1 Universidade Federal do Pará (UFPA), Belém, Pará, Brasil. 


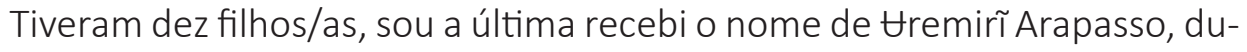
rante minha infância, minha mãe que sofreu muito com a opressão da exploração ocidental, e cedo me alertou para que eu, e meus irmãos pudéssemos estudar, pois ela acreditava, à época, que somente pela educação que alcançasse o ensino superior, é que poderíamos alcançar justiça e manter a nossa determinada resistência como indígenas. Lembro-me das vezes em que ela dizia "ou estuda ou tem roça para plantar", não que o trabalho na roça fosse algo ruim, aliás, sempre que me vem à memória o trabalho da terra, é quase impossível não lembrar dela.

Minha mãe, Mercedes Baré, é uma mulher literalmente guerreira. Mesmo com suas limitações de conhecimentos escolares, nunca permitiu que meus irmãos e eu, ficássemos desamparados nos estudos. Ela e meu pai Olavo Arapasso, tiveram pouca instrução escolar básica, pode-se dizer que de fato nenhuma, apenas meu pai estudou até a quinta série na escolar rural coordenada pela Igreja Católica.

Nossa rotina era sempre a mesma. No meu caso, durante a semana eu ia a escola e nos finais de semana e em feriados, ajudava a família nas atividades da roça.

\section{DO CHAMADO MISSIONÁRIO, AO ENFRENTAMENTO DO RACISMO}

Fiz o ensino Básico na Escola Santa Isabel, sob a direção era por freiras salesianas. E lá no município de Santa Isabel, dei início ao ensino médio, na escola Pe. José Schneider, que não mais era coordenada pela Igreja, mas sim pelo Município. Mais tarde, tive que me transferir para São Gabriel da Cachoeira, onde conclui o segundo grau. Na verdade, a mudança, foi motivada pela experiência vocacional junto a Congregação Salesiana. Em São Gabriel da Cachoeira participei ativamente nos movimentos da Congregação Salesiana.

Enquanto estudante, atuei na Paroquia da Pastoral da Juventude, fui catequista e coordenei o grupo Infância Missionária. E, a partir desse instante, a minha vivência passou a ser exclusivamente dentro da Congregação e na comunidade paroquial, e isso fez com que eu tivesse vontade de seguir a vocação missionária. Consequentemente, fui desenvolvendo minhas funções, chegando a ser assessora do grupo Juventude Católica (JUSC) na Comunidade São Sebastião conhecida como Dabarú. 
Com o objetivo de concluir mais uma das etapas de formação missionária me transferi para a cidade de São Paulo em meados de 2010. Permaneci durante sete meses na capital paulista, durante a estada, me deparei com o preconceito e racismo das noviças que vinham do sul para fazer a mesma formação que eu. Muitos são os episódios dos quais me lembro. O comportamento de algumas companheiras de noviciado, com as quais dividia o quarto, desconfiavam de que eu pudesse roubá-las durante a noite de sono. Internamente, eu sofria com tal injustiça, pois estava compartilhando do mesmo espaço que elas, ao ouvir as ideias e comentários, ficava triste.

Ao passar pela experiência tive a oportunidade de conhecer outras atividades religiosas que envolviam uma maior integração com a sociedade em geral, como por exemplo a Pastoral da Juventude. Naquele momento, tive certeza que o meu lugar não era na Congregação, e sim estar na luta com juventude, que para mim representou aprofundar a busca espiritual. Saindo da Congregação eu poderia fazer muito mais, sobretudo pelo aprendizado, pela experiência boa e, mesmo outras, não tão boas. Eu tinha a possibilidade de, enquanto jovem, me tornar protagonista, queria ser como um pássaro livre, pois na Congregação não me sentia à vontade, eu não era eu mesma, ou melhor, talvez eu não fosse quem realmente queria ser. Assim refletindo, decidi voltar para o Amazonas, para perto do meu povo.

Logo após o meu retorno, sofremos a perda do meu irmão mais velho, que era professor, o primeiro da família a ter a Graduação (Proformar/Universidade Estadual do Amazonas [UEA]). Ele lecionava em uma comunidade indígena no Rio Içana. Em umas das suas viagem a trabalho, seu barco naufragou. Não consigo descrever em palavras a dor de meus pais, para eles, era muito difícil lidar com a expectativa de aguardar a chegada do filho professor, afinal ele não mais chegaria!

No ano de 2012, iniciei o trabalho na coordenação da Pastoral da Juventude de Santa Isabel do Rio Negro (PJSIRN) e, ao mesmo tempo, passei a realizar trabaIhos voluntários na Associação das Comunidades Indígenas do Médio Rio Negro (ACIMRN) e dessa forma comecei a acompanhar a luta, os projetos e as reuniões da Associação, à época surgiu a oportunidade de ser contratada como auxiliar bibliotecário da Escola Municipal Tenente Brigadeiro.

E assim caminhando, fui sentindo necessidade de avançar nos estudos. A minha primeira tentativa de ingressar no ensino superior, veio pela seleção para 
povos indígenas da Universidade de Brasília (UnB), no ano de 2011. Não fui aprovada e, desde então, me debrucei sobre nas atividades da Pastoral da Juventude e da ACIMRN. O tempo passou e eu ouvi falar do Processo Seletivo Especial para Povos Indígenas que acontece todos os anos, desde 2009, promovido pela Universidade Federal do Pará, pioneira na adoção de políticas afirmativas para povos indígenas.

A minha segunda tentativa de ingressar no ensino superior foi na UFPA, uma vez mais não consegui êxito, algo estava errado, comecei a refletir sobre o insucesso. Analisando as duas primeiras tentativas, descobri que os cursos que pretendia, eram os de maior concorrência, justamente Medicina. São apenas duas vagas para povos indígenas e a maioria dos parentes (termo comumente utilizado pelos povos indígenas, ao se reconhecer, independente de parentesco) optavam por este curso. Foi assim que juntando outras questões, sai em busca de que tipo de formação eu precisava para ajudar o meu povo? Que tipo de retorno eu poderia oferecer de melhor para os povos indígenas? E mudei...

No ano de 2016, fui aprovada no curso de Administração pela Universidade Federal do Pará, e decidi que iria ser não apenas gestora, mas uma futura administradora que pudesse melhor articular as questões indígenas que por muito tempo tem sido gerenciada por não indígenas.

A entrar na Universidade, desde o primeiro momento, eu fui alertada sobre o preconceito e racismo com que os indígenas eram tratados. Então, fui munida de toda a segurança que minha família e meu povo me passou bem antes de viajar. Eu sabia que tinha que ter sempre em mente que ninguém, além do meu povo, conhecia a minha história e o que eu passei até chegar no banco de uma sala de aula universitária. Passei pelos semestres com muitas dificuldades, algumas delas veio não somente da minha dificuldade em compreender, mas também das práticas pedagógicas utilizadas pelos professores ao ministrar suas aulas. Infelizmente me deparei com falhas institucionais que jamais imaginei que pudessem acontecer em uma Instituição de renome como a UFPA. Percebi que teria de caminhar sozinha em muitos momentos.

Em contrapartida, conheci e me afiliei em uma organização sem fins lucrativos que amparava o estudante indígena em sua entrada e permanência acadêmica. A Associação dos Povos Indígenas Estudantes na Universidade Federal do Pará (APYEUFPA) criada pelos próprios indígenas estudantes que ingressaram na UFPA, nas primeiras edições do Processo Seletivo Especial (PSE). 


\section{EM BELÉM DO PARÁ}

Quando escrevo sobre o começo da minha graduação, gosto de começar pelas minhas dificuldades vir para Belém, pois não contava com uma certa viabilidade financeira para me movimentar de avião. Então, comprei minha passagem de barco e viajei por quatro dias, naveguei por muitos rios, pelo Rio Negro até encontrar o Rio Solimões, depois o Amazonas, e finalmente cheguei!

Matriculada no curso de administração, eu passei a frequentar cotidianamente as aulas pelo turno da manhã. Durante o resto do dia, permanecia o máximo de tempo que podia dentro do Campus, usufruindo da refeição popular no Restaurante Universitário (RU), utilizando as dependências da biblioteca para estudar, descansando em baixo das arvores, olhando o rio Guamá esperando dar a hora de ir jantar no RU. Quando me dava conta, já tinha passado um dia todo, aí eu encarava o translado de Belém a Ananindeua onde fui acolhida, por alguns meses, na casa de uma parente, Putira Sacuena (Eliene Rodrigues) e família. Lá fiquei durantes um ano até. Até que eu pudesse receber a bolsa permanência para me manter de forma independente. Permaneci em Ananindeua (município da área metropolitana de Belém) até janeiro de 2018, quando me mudei para Belém, para mais próximo da Universidade, coloquei a mudança nos planos por conta do cansaço físico da logística de translado.

\section{INSEGURANÇA E VIOLÊNCIA NA CIDADE GRANDE}

O motivo que me fez tomar a decisão de sair de Ananindeua foi que o medo de morar naquele local, consumia meus pensamentos. O kitnet em que eu morava foi invadido por dois homens se dizendo da polícia, e vejam, eu moro com dois jovens do Rio Negro, uma moça e um rapaz. No bloco em frente, outros dois jovens vindos da mesma região, portanto nos conhecemos antes de chegar a Belém. Todos juntos sentíamos segurança, mas... Ainda não sei o real motivo da invasão, mas foi ruim e nos traumatizou, acordamos assustadas, pois os dois caras disseram estar à procura dos meninos que com eles tinham dívida. Os homens bateram nos meus amigos e eu atordoada sem entender o que estava acontecendo, tentei tomar informações sobre a ocorrência e acabei agredida, bateram no meu rosto. Ainda carrego sentimentos ruins deste episódio, pois foi inesperado 
e ainda desconheço o que levou aos agressores fazerem tal brutalidade com os meus amigos.

É comum os indígenas veteranos abrigarem os outros, na verdade, os veteranos acabam sendo referência para os parentes que se encontram em nossas aldeias. Em relação a situação de moradia ou como na academia dizem "permanência" tivemos que lutar, nós estudantes indígenas, novatos e veteranos, graduandos e pós-graduandos por uma mesma finalidade, a permanência adequada dos estudantes indígenas no ensino superior público.

Em meio a reuniões, os membros da APYEUFPA discutiam nossas carências e como podíamos superá-las via programas institucionais. Foram, e ainda são muitos os debates que temos isoladamente, antes de levarmos a mesa da Reitoria, nossas reivindicações. A meu ver, uma das atribuições de maior importância da Associação é levar os assuntos pontuais às reitorias das instituições que nos abrigam como estudantes, pois, foi esse tipo de atitude que fez com que estreitássemos mais as nossas parcerias com outros núcleos do Campus. Realizamos e fomos convidados em muitas rodas de conversas, seminários, debates. Fizemos tudo que o que foi preciso para que a "comunidade acadêmica" nos notasse, e assim aconteceu.

\section{Na faculdade de Administração}

Ao receber o resultado de aprovação no curso de Administração, fui orientada quanto ao processo de encaminhar ao Centro de Registro de Indicadores Acadêmicos (CIAC), na UFPA, e logo pude perceber como a burocracia faria parte incessante da minha vida.

A Faculdade de Administração como todos os cursos da UFPA possui disciplinas introdutórias, que permite que ao discente, uma compreensão panorâmica dos conhecimentos na área, afim de que os estudantes possam estar "nivelados" para as disciplinas específicas que se iniciam a partir do segundo semestre letivo. Todavia, quando faço um retrospecto percebo que o curso possui uma grade curricular desatualizada em que não abarca muito do que se é necessário para a formação de um administrador no Brasil, especialmente de uma indígena que se pretende administradora.

Hoje reflito como indígena e futura administradora, que a educação superior pública deste país, sobretudo a do Norte, precisa fixar-se de maneira mais próxima 
de nossa realidade econômica e social, para que crescimento do Brasil, seja um desenvolvimento honesto e respeite a diversidade presente na Amazônia, sem saquear nossas riquezas naturais.

As dificuldades com as disciplina e os conteúdos que incluem contas e cálculos, sem dúvida, eram as mais difíceis para mim e para quase todos os colegas de turma. Ao entrar no curso conheci outra pessoa indígena, Evelyn Xipaya, oriunda do hoje município de Altamira no Pará, ela me relatou ter desistido do curso em um dado momento, em que não se identificava, mas que resolveu tentar novamente dois anos depois, e,em alguns momentos pudemos nos apoiar enquanto indígenas mulheres dentro de uma faculdade altamente machista e racista. Alguns trabalhos acadêmicos, Evelyn pode me ajudar enquanto eu tentava avançar em outros. Lembro-me de em uma semana, muitos eram os trabalhos a serem entregues e em curto espaço de tempo, para que se compensasse os atrasos gerados pelas greves.

Enquanto estudava, a APYEUFPA crescia. No ano de 2016, o professor Emmanuel Tourinho elegeu-se a reitor da Universidade, juntamente com seu vice, professor Gilmar. Ambos nos procuraram para conhecer a Associação e suas principais demandas que ao longo dos anos vínhamos reivindicando. Selamos o compromisso de apoiá-lo enquanto Reitor, em troca de que ele pudesse enxergar os indígenas com um olhar desprovido de preconceito, racismo e, principalmente, que ele e sua gestão nos convidasse enquanto associação de estudantes indígenas, à participar e se possível, deliberar sobre o ingresso e as condições de permanência de indígenas na UFPA por intermédio das Políticas de Ações Afirmativas.

\section{Construindo e testemunhando resultados}

O ano de 2017, foi o ano em que colhemos alguns frutos que vínhamos lutando em semear. Isso porque os primeiros parentes que ingressaram em 2010, 2011 e 2012, vinham trabalhando em unidade para a construção da APYEUFPA, de forma que ela pudesse representar todos os indígenas da UFPA, para isso, precisávamos de estrutura física e autonomia. Na necessidade de somar forças, a APYEUFPA juntamente com outras associações e movimentos sociais respondeu presente no Campus, somaram para a eleição do novo reitor. 
Conquistamos uma sala equipada, em 2017, e no ano seguinte recebemos a Capela Ecumênica do campus básico da UFPA, e a batizamos ela de "maloca" nossas atividades culturais passaram a ser realizadas no espaço da Maloca, assim, as pessoas pudem ver e ouvir nossa atividades, conquistamos dessa forma maior visibilidade. Alguns professores se mostraram parceiros e interessados em fazer algo pela educação dos indígenas de cursos da área da saúde. Os primeiros programas de tutorias para povos indígenas, aconteceram através do Instituto de Ciências Biológicas (ICB) na UFPA. A melhora no aprendizado foi gradativo e teve efeitos sociais positivos, no final do ano de 2018 , os programas de tutoria específicos para indígenas, foram formulados pelo Instituto de Ciências Sociais Aplicadas (ICSA) e pelo Instituto de Ciências Jurídicas (ICJ) estão iniciados oferecendo-nos apoio.

\section{Fora da sala de aula, muitas conquistas}

Outro espaço muito importante que nós conquistamos, foi a participação e a possibilidade de deliberar em conjunto com o Diretório Central de Estudantes (DCE). Foi neste momento que me dei conta da minha atuação. Participava ativamente das reuniões, pois a medida que me importava estar a par de decisões do Conselho Superior de Ensino, Pesquisa e Extensão (CONSEPE) e percebia que nós deveríamos estar próximos das lideranças estudantis a fim de unir forças na busca pelo direito a permanência digna do estudante dentro das universidades. Atualmente além do CONSEPE, temos representatividade no Conselho Superior de Administração (CONSAD) e no Diretório de Movimentos Sociais. Consequentemente temos assento no Conselho Universitário.

A minha experiência com o DCE foi ativa, pude acompanhar todo o processo da campanha que nos rendeu vitória e a partir desse momento fomos cada vez mais nos inserindo no movimento estudantil, enquanto a APYUFPA. Participei em 2017 no 57ㅇ. Congresso da União Nacional dos Estudantes (UNE) uma experiência de suma importância para a representatividade da APYEUFPA nesses espaços, Resgatando a experiência que tive com a Pastoral da Juventude, contribuo com as lutas junto aos movimentos sociais e fui aprendendo a me identificar e, hoje, participo do Levante Popular da Juventude (LPJ), no qual tem sido parceira de luta junto com os estudantes indígenas. 
Algo muito significativo também, foi o Encontro Nacional dos Estudantes Indígenas (ENEI), em 2016, em Santarém-PA e, em 2017, em Salvador-BA, um espaço de partilha, sobre diversos temas voltados à educação, à saúde, à resistência e à permanência junto com os parentes discentes universitários de todas as regiões. Volto sempre renovada dos eventos, pois encontrar com outros parentes, saber dos demais povos aprendendo com as suas especificidades e compartilhando situações parecidas com a minha, isso me ajuda a entender que não estou só na luta.

\section{Eu serei resistência junto com meu povo}

Atualmente, me encontro no penúltimo semestre de Administração e fui eleita a nova presidente da APYEUFPA. O sentimento que tinha de que não alcançaria grandes coisas, hoje, não existe mais, pois analiso e leio de tudo que aconteceu, e consigo me enxergar um destino do qual não posso me desviar, especialmente quando olho para os 23 povos da minha região e percebo, sinto como eles esperam que eu ajude na luta pela nossa resistência. Tenho minhas limitações, no entanto, a força que vem da união dos parentes, tanto da base, quanto da cidade, me faz acreditar que posso alçar voos altos. Olho para o nosso cenário político e me entristeço, me revolta ver o retrocesso que os povos indígenas estão a sofrer, mas não desisto!

Hoje eu entendo melhor o propósito de eu vir de tão longe. Preciso estudar para ter propriedade em debater politicamente as questões indígenas, mas sobretudo, preciso me fortalecer honrando os meus ancestrais, eu sei que eles estão comigo, por onde eu caminhar. Nossa luta hoje é para validar o sangue que foi derramado desde que o branco empurrou goela a baixo o seu modo de vida em nossas aldeias. Agora, usaremos do nosso poder e sabedoria indígenas somados aos conhecimentos do homem branco, e assim mostraremos o quão honesta e justa é a nossa busca por respeito e reparo desta sociedade com os povos indígenas da Amazônia, do Brasil e do mundo. 


\section{Sobre a autora:}

Virgínia Braga Fonseca - De pertença Arapasso. Graduanda no Curso de Administração da Universidade Federal do Pará (UFPA). Presidenta da Associação dos Povos Indígenas estudantes da Universidade Federal do Pará (APYEUFPA). E-mail: arapassovirginia@gmail.com

Recebido em 2 de março de 2019

Aprovado para publicação em 13 de maio de 2019 